\title{
«GONZÁLEZ ES MI NOMBRE»: POEMAS DESCONOCIDOS DE LOPE DE VEGA EN UN CERTAMEN POÉTICO (1614)
}

\author{
ELENA DEL Río PARRA \\ Brown University
}

En 1622 sale en Madrid, de la imprenta de la viuda de Alonso Martín, la Relación de las fiestas que la insigne Villa de Madrid hizo en la canonización de su bienaventurado hijo, y patrón San Isidro, con las comedias que se representaron, y los versos que en la justa poética se escrivieron. En ella Lope de Vega, bajo la máscara de Tomé de Burguillos, recordaba su participación en el certamen celebrado con motivo de la beatificación de Teresa de Jesús con los siguientes versos:

En vuestras primeras fiestas

me dieron de premio un cáliz

$\mathrm{y}$ me dejaron entrar

en la huerta aquellos padres.

Efectivamente, Lope de Vega actuó como juez de esas primeras fiestas de 1614, cuyo contenido se publica al año siguiente formando parte de un volumen que recopila fray Diego de San José bajo el título de Compendio de las solenes fiestas que en toda España se hicieron en la Beatificación de N. B. M. Teresa de Jesús fundadora de la Reformación de Descalzos y Descalzas de N. S. del Carmen. En prosa y verso'.

Joaquín de Entrambasaguas acota el fragmento anterior para explicar cómo Lope tuvo el privilegio de entrar en la huerta del convento de San Hermenegildo y de llevarse cuanta fruta quiso de allí puesto que, al parecer, no cobró nada por ejercer de secretario del certamen ${ }^{2}$. Añade Entrambasaguas

\footnotetext{
1 También aparece publicado, sin año y sin lugar, bajo el título de Relación de las fiestas que en la Beatificación de Nuestra Madre S. Teresa se celebraron en estos dos Conventos nuestros de Madrid S. Hermenegildo y S. Ana.

${ }^{2}$ «Datos acerca de Lope de Vega en una relación de fiestas del siglo XVII», Estudios sobre Lope de Vega, vol. II, Madrid, Consejo Superior de Investigaciones Científicas, 1947, pág. 586.
} 
que la participación de Lope en las justas de 1614 se limitó a dos composiciones, ya que se abstuvo «de concurrir a premio alguno ni de presentar tampoco ninguna composición bajo nombre supuesto, más o menos familiar» ${ }^{3}$.

Las composiciones firmadas por Lope de Vega son la «Oración y discurso que para dar principio al certamen poético hizo Lope de Vega en alabanza de N. M. S. Teresa de Jesús» (4v), que comienza «Platón muriendo (o noble, heroyco, ilustre / grave y docto Senado) dijo alegre...». La otra es un romance que figura al final de las condiciones del certamen (13v) y comienza «Publicado este cartel»; en él, Lope relata la entrada de los poetas en el huerto del convento y comenta a modo de vejamen algunos de los poemas presentados - especialmente los sonetos-, por lo que se deduce que este romance es posterior a la justa ${ }^{4}$.

Pero volvamos a la afirmación de Tomé de Burguillos: efectivamente, le dejaron entrar en la huerta pero, si hacemos caso de su buena fe, también ganó un premio. El premio o «precio» sólo puede ganarse participando en alguno de los certámenes, nunca como pago por juzgar o editar los poemas posteriormente. No es difícil comprobar cómo Lope, siempre que estuvo presente en una justa, concurrió con varios poemas «al premio». A veces firmó como Lope de Vega; a veces lo hizo con el conocido seudónimo de Tomé de Burguillos, que luego retoma en las Rimas humanas y divinas del Licenciado Tomé de Burguillos, su poemario final aparecido en 1634. En otras ocasiones, Entrambasaguas atribuye justamente a la pluma de Lope poemas firmados por Hernando Gandío ${ }^{5}$, si bien a veces la asignación sigue siendo dudosa y difícil de demostrar en el caso de seudónimos como Lucinda Serrana, Lope de Vega «el mozo», doña Antonia de Nevares o el doctor don Pelayo Resura ${ }^{6}$. Pero de lo que no cabe duda es de que Lope jamás se resistió a participar y a componer poemas para las justas; nunca quedó relegado a mero compilador y editor de las composiciones de otros, o a mantenedor de la justa.

La justa de 1614 propone ocho certámenes: lo dos primeros consisten en un «epigrama latino» y un «himno latino» y los que les siguen son, respectivamente, una canción castellana, un romance, una glosa, un jeroglífico y un soneto con los consonantes forzados. Desgraciadamente, ninguna de las ediciones de esta justa de 1614 cuenta con la relación de ganadores, aunque sí

\footnotetext{
${ }^{3}$ Lope de Vega en las justas poéticas toledanas de 1605 y 1608, Madrid, s.e., 1969, pág. 18.

${ }^{4}$ Aunque el romance no está firmado, el ejemplar del citado Compendio que se halla en la Biblioteca Nacional de Madrid tiene escrito al margen el nombre de «Lope de Vega».

${ }^{5}$ Cf. Lope de Vega en las justas poéticas toledanas de 1605 y 1608, ed. cit., págs. 120-121.

${ }^{6}$ Cf. «Las justas poéticas en honor de San Isidro, en relación con Lope de Vega», Anales del Instituto de Estudios Madrileños, vol. IV, Madrid, Consejo Superior de Investigaciones Científicas, 1969.
} 
tenemos constancia de los premios ofrecidos. Todas las piezas de plata que se dan como primer premio son para los certámenes «de romance»: un jarro de plata para el tercero, un barco de plata para el quinto, una salvilla de plata para el sexto y «una pieza de plata muy curiosa» para el séptimo. No se menciona específicamente un cáliz, por lo que sólo queda la posibilidad de que ese premio al que se refiere Tomé de Burguillos en 1620 sea la curiosa pieza de plata que se dio como recompensa al mejor soneto.

El editor de la justa poética se detiene en advertir que se presentaron infinidad de composiciones al certamen, y que muchas de ellas no pudieron ser recopiladas:

huvo en este certamen otros muchos que no se ponen aquí, parte por excusar la prolijidad, y lo principal porque aunque huvo todo el cuidado y vigilancia posible en conservarlos mientras la fiesta duró, y en recogerlos después, de los mejores faltaron algunos, sin que toda esa providencia fuese bastante a defenderlos porque personas curiosas, que saben hacer estima y aprecio de lo que es digno del, andavan codiciosísimos de llevárselos.

Como consecuencia, sólo se publicaron cinco sonetos de entre todos los presentados. Uno de ellos, el último, viene firmado por un tal «González el estudiante». Los poemas de este personaje aparece cerrando los cinco certámenes «de romance», a pesar de que se persigue la prolijidad de la justa poética. Es difícil de explicar la aparición reiterada de un estudiante desconocido en una prueba donde participaron autores de prestigio, Miguel de Cervantes entre otros, y el nombre se hace poco menos que sospechoso.

La fórmula de presentación también es atípica: de ser un poeta poco conocido lo más corriente hubiera sido presentarlo como «González, estudiante», nombrando seguramente el lugar donde cursara estudios. Ese reiterado «González el estudiante» hace pensar que se trata de alguien conocido de todos los presentes en el certamen. El soneto en cuestión es el siguiente ${ }^{7}$ :

De González el estudiante a los consonantes

\section{SONETO}

¿Qué piedra de amolar me dará un Filo?

que pierdo el seso de la noche al Alva

por saber las virtudes de la Malva

$\mathrm{y}$ al quarto verso acomodar el Nilo.

\footnotetext{
${ }^{7}$ A efectos de seguir el texto con la mayor fiabilidad posible, si bien sacrificando criterios modernos de puntuación y grafía, altero todos los poemas sólo en lo imprescindible. Los cambios se resumen en acentuación de palabras y supresión de consonantes dobles, iniciales a principio de verso e iniciales esporádicas. La puntuación queda intacta, en detrimento del sentido.
} 
$5 \quad$ Ya mi musa con bueno, o mal Estilo deste primer quarteto queda Salva, mas, ¿cómo agora encaxaré la Calva, y en el otavo verso a San Cirilo?

Quartetos fuera, los tercetos se Armen, 10 más ¿qué diré de vos, si tantos Sabios os suben a tan altas Gerarquías?

Teresa, Dios os hizo para el Carmen, yo pongo en vuestros pies mis rudos Labios; el soneto acabé, gracias a Elías.

Los consonantes fueron especialmente difíciles de seguir y Lope, que seguramente fue quien los propuso, se para a comentar en el romance inicial la curiosas - a veces descabelladas - soluciones de los sonetos presentados ${ }^{8}$. González sale airoso del trance con un soneto autorreferencial que nada tiene que ver con el significado de los consonantes forzados, limitándose a encajarlos en el sitio correspondiente. Recordemos que Lope se había servido de una técnica similar en «Un soneto me manda hacer Violante», contenido en La niña de plata, comedia de hacia 1610-13; en dicha composición, como en ésta, el soneto se formula a sí mismo mientras se va construyendo.

Como en su día apuntaran en sendas notas Joaquín de Entrambasaguas ${ }^{9}$ y José Manuel Blecua ${ }^{10}$, el último libro de poemas de Lope se compone de algunos escritos muy anteriores a la fecha de su publicación. Efectivamente, la cubierta nos avisa de que las Rimas humanas y divinas no están «sacadas de biblioteca ninguna (que en castellano se llama librería), sino de papeles de amigos y borradores suyos». Como ejemplo de ello suele señalarse la reescritura del romance que comienza «Ya, pues, que todo el mundo mis pasiones / de mis versos presume». Este poema apareció en las Flores de poetas ilustres de Pedro de Espinosa - cuya aprobación, recordemos, data de 1603 - , pero se adapta bien al conjunto de las «Rimas humanas» aparecidas en 1634.

Del mismo modo, el penúltimo poema de las «Rimas divinas» - la parte más olvidada del libro- resulta ser nada menos que el arreglo de un romance aparecido en el cuarto certamen de las justas de 1614. En las Rimas humanas y divinas la composición lleva el epígrafe «A San Hermenegildo,

\footnotetext{
${ }^{8}$ «Y el soneto, con más calvas / que desde el diluvio ha hecho / el mal de Francia en los mozos / y el mal del tiempo en los viejos; / ... / no ha hecho tantos guisados / el cocinero más diestro / como ellos de aquesta calva / por buscarle algún remedio. / Calvas hubo en escabeche, / y de gigotes diversos, / ... / El consonante de Malva / mil boticarios han hecho, / como si fuera lugar / de emplastos y cocimientos».

9 «Las justas poéticas en honor de San Isidro, en relación con Lope de Vega», ed. cit., pág. 100 , nota 149

${ }^{10}$ Lope de Vega, Obras poéticas, Madrid, Planeta, 1989, pág. 1230.
} 
en los premios de la justa a la Santa Madre, Teresa de Jesús» (nótese de nuevo la referencia al «premio»). En el impreso de 1615 el romance va encabezado por el epígrafe de «González el estudiante» y, si bien la variación es mínima, se notan ciertas alteraciones y retoques que tienen que ver más con el estilo que con el significado, y a veces simplemente consisten en un cambio de grafía. De todos los poemas presentados por el estudiante, éste resulta ser el menos circunstancial, y por tanto el más susceptible de ser incluido en un contexto diferente, al presentar sólo una referencia en primera persona («yo, poeta adocenado») ${ }^{11}$.

De González el estudiante. Romance

Leovigildo rey cruel, nombre que en León comiença, más símbolo de crueldad que de heroyca fortaleza.

$5 \quad$ Manda que muera su hijo; mas con mucha diferencia de Dios, que no perdonó al que eternamente engendra. Porque Dios a Dios pagase

10 de nuestras culpas las deudas, pues sólo el caudal de Dios pudiera satisfazellas. Temiendo perder el reyno manda que su hijo muera,

15 porque con el Rey del cielo le dizen que se cartea. Parte un verdugo a sangrar de Hermenigildo las venas que tiene sangre del padre,

20 y quiere Dios que se vierta. Yva sobre el monte Moria el tierno Isac con la leña, y el viejo Abrahan su padre alegre de su obediencia.

25 Para que diga el Apóstol, que una fe tan verdadera

\footnotetext{
"Lo transcribo anotando las variantes que, aunque mínimas, son de destacar: v. 14, mandó que su hijo muera; v. 16, le han dicho que se cartea; v. 18, de Hermenegildo las venas; v. 19 , que tienen sangre del padre; v. 27 , se le atribuya a justicia; v. 32 , en su misma ligereza; v. 49 , Yo, poeta adocenado, v. 53 , Va de sayón en bosquejo; v. 60 , la cara a remiendos hecha; v. 64, tuviera el infierno pena; v. 70 , era un pepino badea; v. 84 , de curtidor de baquetas; v. 86, a las rodillas no llega; v. 90, de un tahelí puesto que lleva; v. 91, un hacha de armas; v. 94, mas de golpe diferencia; v. 98, por señas de su pureza; v. 106, bordan, entre oro y perlas; v. 115, que habéis vos de ser un hacha.
} 
se le atribuye a justicia, que en tantos hijos se premia. Y de la ciudad de Dios,

30 para que el braço le tenga, un Ángel toma la posta con su misma ligereza. Tiene el brazo de Abrahan que Dios corazones prueua

35 mas al rey godo al contrario libre execución le dexa. Pero ¿quién me mete a mí en negocios para escuelas?, latines para romances

40 es hablar griego en Illescas. Pinten Príncipe de España otros famosos poetas, vuestra hermosura en la cárcel, vuestra fe, vuestrạ paciencia.

45 Los ángeles que os animan y que por los ayres siembran maná de lirios azules y cándidas azucenas. Que yo poeta adocenado

50 sólo tomaré licencia para pintar los verdugos de vuestar heroyca tragedia. Va del sayón en bosquejo a quien el rey encomienda

55 vuestra muerte, y vuestra vida, una breve, y otra eterna. Érase un fiero verdugo, con la color verdinegra de mulato con quartana,

60 la cara remiendos hecha. Por ánimas de sus ojos estauan dos niñas viejas que a penar en el infierno dieran al infierno pena.

65 Para vestidos de agora, que de guarnición los pueblan, poco valieran los ojos, porque sin pestañas eran. La moquífera nariz

70 era un pepino, vadea, esmaltada de verrugas, forma y color de cerezas. Más de blasfemias que barbas la boca estaua compuesta:

75 los labios de dos salchichas, 
y de un pimiento la lengua.

Los dientes eran hidalgos de Ávila, de quien cuentan que están sobre los asientos

80 toda la vida en pendencia. Desnudo el sangriento brazo, más que de mujer casera el día que hace menudo de curtidor de vaquetas.

85 Una cota a lo romano, que a las rodillas no llega por no ver piernas tan malas ¡o sayón de malas piernas! Pendiente un alfange alarbe

90 de un tahalí puesto que lleva una hacha de armas, que Dios tiene montes y haze leña. Cortar quiso el árbol santo mas el golpe diferencia,

95 que a otros dan por las rayzes y a este dan por la cabeça. El mancebo ilustre entonces por señal de su pureza con una túnica blanca

100 la estola de sangre espera. Déxale el golpe en la frente como una granada abierta porque fruta coronada bien es que de reyes sea.

105 Los granos bueltos granates bordan entre el oro y perlas la talar túnica, y buelven púrpura la blanca tela. Este espectáculo vivo

110 mirando estaba Teresa, Teresa mujer de chapa, Teresa, Madre, y donzella. Del hacha teneys codicia, pues Madre tened paciencia,

115 que haveys vos de ser una hacha que alumbre toda la Iglesia. Que a morir vos de siete años no hubiera esta tarde fiesta en el Convento del Carmen,

120 ni tanto poeta hubiera. Tanto que los hijos vuestros si no es que Dios lo remedia como a otros comen piojos se han de comer de poetas. 
Parece que la aseveración inicial de Tomé de Burguillos era fiable, y puede concluirse que Lope participó activamente en la justa de 1614 bajo el seudónimo de «González el estudiante», que es quien firma el soneto y romance ya comentados, así como una canción, una glosa y un jeroglífico.

Algunos motivos de este romance, como la descripción del atuendo morisco (vv. 89-90), son muy del gusto de Lope, quien hace uso constante de ellos en sus romances. Por su parte, la caracterización del verdugo (vv. 7780) se repite en la comedia El Marqués de las Navas ${ }^{12}$, cuando Mendoza exclama: «Que no puede enamorar / la boca donde los dientes / sobre los asientos riñen / como hidalgos montañeses». La identificación de la sangre con una vestidura (v. 108) es también un motivo propio del romancero viejo tradicional ${ }^{13}$ que Lope aprovechó para su propio corpus romanceril.

Otras referencias no son tan usuales, puesto que remiten a hechos muy concretos: el verso 111 probablemente se refiera a la imagen de la Santa conservada en Alba de Tormes, descrita en el Compendio ${ }^{14}$. No es de extrañar la familiaridad de Lope con el lugar si atendemos al comentario que hace en la "Oración y discurso» de la justa de 1614 y en el romance de Burguillos al certamen de 1620, agradeciéndole la curación de un brazo durante el tiempo que sirvió al Duque don Antonio Álvarez de Toledo ${ }^{15}$.

Este disfraz, que inexplicablemente había pasado desapercibido hasta ahora, concuerda, sin embargo, con muchos de los signos distintivos del futuro Tomé de Burguillos. Prueba de ello es la reutilización de un poema escrito bajo la máscara de González que, sin apenas cambio, puede servir al carácter del licenciado. Pero hay otros rasgos que suelen identificarse como distintivos de Burguillos que ya están presentes en las fiestas de canonización de Teresa de Jesús. Como el Tomé de las justas poéticas de 1620 y $1622^{16}$, González el estudiante se presenta en sus poemas como un perso-

12 1624, jornada I. Para las estimaciones relativas a comedias sigo el que es hasta la fecha único estudio global, realizado por S. Griswold Morley y Courtney Bruerton: Cronologia de las comedias de Lope de Vega, Madrid, Gredos, 1968.

${ }_{13}$ Por ejemplo, en dos versiones del romance de Bernal Francés: «te he de dar rico vestir: / vestido de fina grana / forrado de carmesí, / y gargantilla encarnada / como en damas nunca vi: / gargantilla de mi espada / que tu cuello va a ceñir»; «te haré un vestido de grana / forrado con carmesí, / la gargantilla, la sangre / que vea correr por ti. / Gargantilla de mi espada / que tu cuello va a ceñir».

14 «Tanto era el resplandor que de sí arrojaban diamantes, zafiros, rubíes, esmeraldas y las otras piedras preciosas de las joyas que guarnecían el vestido de la Santa, heridas con las llamas de tantas hachas y velas, que deslumbraban los ojos más perspicaces».

${ }^{15}$ Hecho que comenta extensamente J. de Entrambasaguas en Estudios sobre Lope de Vega, ed. cit., págs. 277-278.

${ }^{16}$ El impreso de 1620 lleva el título de Justa poética y alabanzas justas que hizo la insigne Villa de Madrid al bienaventurado San Isidro en las Fiestas de su Beatificación, Madrid, Viuda de Alonso Martín. 
naje hambriento, que aspira al premio para poder comer, y que olvida alabar al sujeto para centrarse en su propia persona de manera jocosa. En la canción del tercer certamen se nos da cuenta de sus aspiraciones y modo de vida:

De González el estudiante, a los éxtasis de N. S. M. Teresa

\section{CANCIÓN}

Virgen, un estudiante que os parece en los éxtasis algo, que no en todo, con gran necesidad al premio viene: si de temeridad nombre merece,

5 esta proposición, oyd el modo, y entenderéis los éxtasis que tiene, que si en todo conviene la cosa comparada, pudiera ser llamada

10 identidad, y así es la diferencia en que los vuestros son en la presencia real del mismo Dios, y son los míos de hambre sin paciencia, que me obliga a deziros desvaríos.

15 Si vos Virgen divina, de amor puro, sin comer transformada en la hermosura que tiene al Sabio Serafin atento, estays un día; yo os prometo y juro que a mí me aconteció por hambre pura

20 estar dos días transformado en viento. Vos con aquel contento de ver sus perfecciones, las humanas acciones perdeys; y yo de hambre de tal suerte

25 que llego por instantes a la muerte: mirad si son mis éxtasis burlando, que en salve me convierte estar siempre gimiendo y suspirando.

Cuando vos con dulcísimos amores

30 pedís, Teresa, flores desmayada, y mançanitas con melindre santo: yo pido el fruto de las mismas flores, y a la cama de un príncipe dorada comiera las mançanas, entre tanto.

35 A Christo sacrosanto, que hiciese pan dezía de piedras cierto día, la estrella que cayó del sol, al suelo; y a mí para más pena y desconsuelo, 
40 el pan me buelve piedras, de tal modo, que no lloviendo el cielo, cuanto agora me dan es piedra todo.

Pedid a vuestro Elías, Virgen santa, quite las cataratas de los cielos,

45 que vale un pan un real, y es fuerte caso. Mas volviendo al asumpto que os levanta al arca que en Dios puso tantos velos; oyd a vuestro hambriento Garcilaso, que oy ayuna el traspaso.

50 Ya de comer se olvida por falta de comida, que no por buena gana, que le sobra, ya el gusto no es sentido, ni en la obra. Sólo en mí come sarna estudiantesca,

55 que sus raciones cobra, por tenerla las uñas siempre fresca.

A vos en esos réxtasis divinos, christífera Teresa, cantan coros angélicos, en cítaras suaves,

60 psalmos, sonetos, madrigales, hymnos: y a mí por los oydos, por los poros entran agudas voces, más que graves, de las terrestres aves, gallinas, y capones,

65 cabritos, y lechones, que tales son los éxtasis que toco, con tal flaqueza, que me buelvo loco; mas no me quitan Virgen celebraros, que como peso poco

70 me voy tras vos por esos ayres claros.

No piensen ignorantes (de que ay tantos) que mezclo con lo humano lo divino; porque dar de comer al que hambre tiene, es obra de piedad, que a muchos santos

75 abrió del cielo el arco cristalino. $\mathrm{Y}$ así mi Musa al santo Carmen viene, pues en él se mantiene: sin esto pido el premio (o religioso gremio)

80 pues más sutil celebro su grandeza, si la hambre es la misma sutileza: tanto que digo que es su pie descalço, del Carmelo cabeça,

Dios su laurel, porque hasta Dios le ensalço.

85 Canción, si merecieres premio alguno, tres días ha que ayuno, será bien empleado, hambriento escribo, Gonçalez es mi nombre, al rastro vivo, 
que el sábado me ha dado por posada,

90 mi suerte desdichada;

aunque en el ayunar, soy Viernes Santo.

Mas si enfadares, como pobre tanto

y a los críticos fueres importuna,

diles (baxando el canto)

95 que la hambre les doy de dos la una.

La filiación directa de Tomé de Burguillos con el estudiante pasa por el hecho de haber vivido en el mismo vecindario, el Rastro, de donde se mudó Burguillos según nos dice en la canción para la justa de 1622: «que al rastro de Madrid donde vivía». Del mismo modo, Tomé de Burguillos declara en sus liras comer en la «capuchina sopa» y González el estudiante vive de la caridad del convento (vv. 76-77), aunque no por ello deja ninguno de pasar hambre. Las concomitancias se acentúan en la última estrofa de ambas canciones, donde el poeta se dirige a la composición, pidiendo solución para su apetito; en la de 1622, Burguillos implora: «Canción, para la hambre que me abrasa, / no me pidas que pase deste paso, / el sol se va al ocaso, / los ángeles al cielo, Isidro a casa / yo a pedir en latín, pero no creo / que a mi deseo de comer alcance, / pues apenas me entienden en romance».

Recordemos que la canción antecede al resto de los poemas que presenta al concurso, por lo que es lógico que en esta última estrofa González el estudiante ofrezca una pequeña autobiografía. También es común la queja - mucho más acentuada en Burguillos- de la sarna, las pulgas, piojos, y otros insectos.

Un extenso artículo de S. Griswold Morley permite contextualizar mínimamente la construcción del seudónimo ${ }^{17}$. Por una parte, Morley señala cómo en este mismo año de 1614 Lope utiliza el sobrenombre de Antonio Flórez para prologar sus Rimas sacras. Por otra, la figura de un estudiante ya había sido disfraz del poeta para solicitar el tan deseado puesto de Cronista real en La ventura sin buscalla, que data de entre 1606-15. Además, el poeta se hace pasar por el licenciado Luis de la Carrera en el prólogo a los Triunfos divinos publicados en 1625. Dámaso Alonso, por su parte, recuerda que Tomé de Burguillos unas veces es licenciado, otras bachiller y otras maestro ${ }^{18}$.

\footnotetext{
17 «The Pseudonyms and Literary Disguises of Lope de Vega», University of California Publications in Modern Philology, XXXVIII, 5, 1951, págs. 421-484. El trabajo ve su continuación en el de Felipe-Antonio Lapuente: «Más sobre los seudónimos de Lope de Vega», Lope de Vega y los origenes del teatro español, ed. de Manuel Criado de Val, Madrid, Edi-6, 1981, págs. 657-669.

${ }_{18}$ Obras completas, vol. II, Madrid, Gredos, 1973, pág. 850. Aunque no dudo del testimonio de D. Alonso no encuentro ninguna referencia donde Burguillos sea bachiller.
} 
No es extraño pensar entonces en un estudiante como nueva máscara del poeta, quien gusta de describir el ambiente universitario en muchas de sus comedias. Ricardo del Arco y Garay hace un recorrido por el repertorio colegial en las comedias de Lope, demostrando el interés del poeta por la clase estudiantil ${ }^{19}$. Por su parte, el estudio que llevaran a cabo Griswold S. Morley y Richard W. Tyler arroja un recuento de noventa estudiantes que, con mayor o menor importancia, pueblan las comedias de Lope ${ }^{20}$. En la primera estrofa de la canción, González aparece utilizando proposiciones de lógica, si bien esta es la única vez que lo vemos aplicando sus conocimientos a la poesía.

El hambre y el premio de la justa como solución vuelve a ser el tema de la glosa. De hecho el estudiante, como Burguillos, se centra más en la recompensa que en las alabanzas, y da la sensación de que el verdadero «sujeto» del poema son los premios y no la futura Santa. He aquí la glosa:

De González el estudiante. Glosa.

Con asombro del profundo

Teresa ilustre mujer

nace el Alva para ser

sol de España, y luz del mundo.

Al buelos mis versos van, mas soy tan pobre guillote que si algún premio me dan, aunque no soy sacerdote

5 le volveré en carne, y pan.

Denme primero, o segundo pues en limosna me fundo, como la que cada día me dan en la portería

10 con asombro del profundo.

Si por ser tan ignorantes, el barco de plata que ay, no embarca mis consonantes apelo para el cambray,

15 y del cambray a los guantes. Mas si os he de encarecer, que es por lo que aquí premiays, digo que deveys de ser (pues tan ricos premios days)

${ }^{19}$ La sociedad española en las obras dramáticas de Lope de Vega, Madrid, Escelier, 1941, págs. 690-703.

${ }_{20}$ Los nombres de personajes en las comedias de Lope de Vega. Estudio de onomatología, parte II, Berkeley y Los Ángeles, University of California Press, 1961. 
20 Teresa ilustre mujer.

Dizen que esta mujer fuerte nació en Alva tan felice, que en ella el sol se convierte, y dice bien quien lo dize,

25 pues fue su vida su muerte. Morir un Santo, es tener vida que de muerte salva, pues si el morir es nacer, no muere Teresa en Alva,

30 nace el Alva para ser.

Muchos Santos tiene Dios

de un mismo nombre en el cielo

Catalinas tiene dos, mas Teresas yo recelo

35 que no tiene más de a vos.

Si en el barco no me hundo

(Virgen) de paño me tundo,

y de vuestra religión

los Padres diré que son

40 sol de España, y luz del mundo.

En la glosa, González el estudiante trata a la beata Teresa con suma familiaridad y se perfila como un holgazán que, como Tomé de Burguillos, vive de la limosna. Ambos además se presentan como poetas de repente, que lanzan sus versos «al vuelo».

En la segunda décima de este poema, como en el verso 71 de la canción, el estudiante se refiere a «los ignorantes» que deben conceder o denegar los premios, esto es, a los jueces. En el prólogo de la justa aparece Lope de Vega como uno de ellos, siendo el resto amigos suyos ${ }^{21}$, por lo que se establece aquí por primera vez el juego que culmina en verdaderas amenazas en la justa de 1620. Si en la glosa presentada González tacha al jurado de ignorante, años después Tomé terminará deseando toda clase de males a Lope de Vega, su fracaso teatral entre otros: «Si comedia escrivieres, plega al cielo / la yerre un jugador representante, / o con las apariencias venga al suelo / nube carpinteril, ángel volante».

Dentro del conjunto de poemas aquí presentado llama especialmente la atención el jeroglífico. Hablando en general, este es el concurso donde menos juegos poéticos suele haber, por tratarse de un sistema muy codificado de símbolos. Los poetas suelen así ceñirse a las imágenes clásicas de la Virgen como rosa, arca, etc., y no aventurarse a idear grandes variaciones. Sí tenemos noticia de jeroglíficos jocosos en fiestas como la de la Purísi-

\footnotetext{
${ }^{21}$ Se trata de don Rodrigo de Castro, don Melchor de Moscoso y don Francisco Chacón.
} 
ma Concepción celebradas en Valencia en 1622. El Colegio de cirujanos adorna su carro con emblemas que comparan a la Virgen con bacías, con una muela de afilar navajas, con una silla de barbero o con unas tenacillas de rizar bigotes ${ }^{22}$ si bien, a su manera, los cirujanos tienen como propósito alabar a la Virgen.

Pero dentro del contexto de una justa poética, sin embargo, no conozco a otro poeta aparte de Lope que componga jeroglíficos de burlas que, además, equivocan el propósito del certamen, como señala el editor de la justa de 1614:

No fue el que menos regozijó nuestra fiesta Gonçalez el estudiante, con las poesías de gracias que traxo a todos los certámenes de romance, cuyo es el siguiente Geroglífico, el qual si no sirvió de lo que otros, por lo menos causó más recreación en el auditorio que las cosas de veras ${ }^{23}$.

El poema llama la atención de inmediato, tanto por la descripción tan peculiar que formula como por la solución al emblema:

Píntese una ratonera armada, y un virote con plumas blancas, con una letra que diga: Arma virumque cano. A un lado se pondrán colgadas tres varas de longaniza, y diga la letra latina. Longanimitas: Al otro se pintará un papagayo, dando voces, y diga la letra. Pontificatus. Después de pintado lo dicho.

Cúbrase esta pintura con una manta, y un garavito, y la letra española diga.

Aquesta emblema pintada,

no la pongan padres míos,

porque es todo desvarios,

y no significa nada.

El jeroglífico que carece de explicación será explotado como recurso por Tomé de Burguillos, quien ensaya los emblemas más detallados: "píntese un queso fresco en la punta de una lança de veynte y cinco palmos». El Tomé de 1620 también insiste en que, una vez pintado el emblema, se cubra «con una cortina que se pueda quitar y poner», a modo de teatrillo.

Como González, Burguillos mezcla las pinturas más absurdas con renombradas fuentes literarias y citas de autoridades y no tiene reparos en salpicar los emblemas con citas de Virgilio, Persio o Quintiliano, sacándo-

\footnotetext{
22 Pilar Pedraza recoge dichas manifestaciones en Barroco efimero en Valencia, Valencia, Ayuntamiento de Valencia, 1982, págs. 158-161.

${ }^{23}$ No tenemos noticia de quién pudo ser el editor de esta justa. Es de notar, sin embargo, que los poemas de González el estudiante, como los de Tomé de Burguillos, cierran cada certamen, y que el romance inicial de Lope fue incluido después del evento.
} 
las de contexto o entreverándolas con latín macarrónico. En la jornada III de la comedia La limpieza no manchada (1618), unos estudiantes ven un cartel y fingen estar en una justa, componiendo poemas en latín macarrónico. Una de las sentencias latinas, Deprehensus est in malitia, se utiliza en un jeroglífico de Burguillos para la justa de 1620 .

Cabe buscar una segunda intención en la elección de todo este elenco de estudiantes, licenciados y maestros. Estudiante, claro, es «el que estudia», pero el Tesoro de Covarrubias, define «el muy docto, que aunque lo sea, siempre estudia y nunca le parece que ha llegado a saber lo que basta, descubriendo cada día cosas nuevas». Autoridades ofrece una segunda definición y un ejemplo de La Dorotea: «el que ha estudiado, y se aplica a saber: y así se dice, Fulano es buen estudiante, tiene buenos principios y sabe»; y como tercera acepción: «Se toma algunas veces por el que observa con atención y cuidado, y procura saber e inquirir las cosas».

No sabemos hasta qué punto Lope está pensando en un estudiante que se afana en saber, en esta acepción secundaria, o en el juego entre ambas. Probablemente hay algo de ironía al elegir la ocupación de estudiante, si atendemos al comentario de Lope en una carta escrita la noche anterior a la justa:

Desde que comenzo, Señor excm. ${ }^{\circ}$, la fiesta de la santa Madre no he tenido en casa más de las noches, y éstas, ocupadas en sus alabanzas, fuera de lo que no ha permitido el sueño... Verdad es que yo he topado con los versos de la tal persona, mui mirados, y, por deçirlo en su lenguaje, çircunspectos, mañana se le dara algo de lo que mereze; que todo no es posible; Vex. ${ }^{a}$ no falte de onrrarme; que con solo ver su cara, me alentaré a mi oraçión balientemente; la qual no pienso deçir de memoria, porque la tengo debil y offendida de tantas ymaginaçiones, y no querria turbarme, para venganza de tanto poeta como me han de estar escuchando ${ }^{24}$.

González de Amezúa no identifica a quién puede referirse Lope pero, como puede notarse, el uso de la ironía no está de más en una justa en la que Lope se encuentra rodeado de amigos, pero donde también habría su sector hostil. Desgraciadamente, ni la «Oración» inicial de Lope ni las alusiones veladas de González el estudiante ofrecen pistas que revelen la identidad de «la tal persona»; puede aventurarse que se trate de Cervantes, presente en la justa, pero no hay ningún dato concluyente al respecto.

Juan Manuel Rozas, aludiendo a la transfiguración de Lope en Burguillos, declara que le interesa «sólo ver que cuando aparece en las justas isi-

\footnotetext{
${ }^{24}$ Lope de Vega en sus cartas, tomo III, ed. de Agustín González de Amezúa, Madrid, Tipografia de archivos, 1941, pág. 167.
} 
driles de 1620 y 1622 es poco más que un seudónimo para poder presentar poemas en un concurso en el que Lope, como mantenedor, no puede abusar de su nombre, y también una forma de separar la poesía burlesca de la grave» ${ }^{25}$. Efectivamente, según González es conveniente no mezclar «con lo humano lo divino», y el seudónimo es una buena forma de evitarlo en el año en que se publican las Rimas sacras. Pero los poemas de Burguillos no son gratuitamente burlescos: en ellos se transgreden de forma constante las leyes de la justa, y presentan rasgos que permiten construir un alter ego con personalidad independiente. Este Tomé llegará a las Rimas de 1634 con las mismas ropas hechas jirones, la misma hambre y sin ningún dinero.

$\mathrm{Y}$ muchos de estos rasgos, como espero haber hecho notar, arrancan de veinte años antes. Puede decirse que el licenciado ha aprendido las buenas artes del estudiante, y las explotará en otras direcciones. La crítica al lenguaje enrevesado o la sensación de no haber sido bien remunerado se irán acentuando, así como el grado de autorreferencialidad de los poemas o el diálogo de Lope con Burguillos y viceversa, llegando a mediar insultos y amenazas, como hemos visto. Pero de lo que no cabe duda es de que Lope supo sacar partido a largo plazo de este pequeño germen que es González, un estudiante pobre en un universo lleno de seudónimos.

${ }^{25}$ Estudios sobre Lope de Vega, Madrid, Cátedra, 1990, pág. 198. 